Área Abierta. Revista de comunicación audiovisual y publicitaria

ISSN: 2530-7592 / ISSNe: 1578-8293

https://dx.doi.org/10.5209/arab.80085

\title{
Enrique Bustamante: colega, vecino y, sobre todo, amigo
}

\author{
Adelaida Bolea de Anta ${ }^{1}$
}

Recibido: 6 de octubre de 2021 / Aceptado: 25 de enero de 2022

Resumen. En el mes de junio de 2021 fallecía a los setenta y dos años Enrique Bustamante Ramírez, catedrático emérito de Comunicación Audiovisual y Publicidad en la Universidad Complutense de Madrid. Adelaida Bolea, profesora honorífica de cátedra, hace un recorrido por alguno de los méritos que marcaron su vida profesional. Sirva este homenaje de Área Abierta a la memoria de uno de los miembros del consejo asesor de la revista.

Palabras clave: Enrique Bustamante; comunicación; industrias culturales; educación; universidad

\section{[en] Enrique Bustamante: Colleague, Neighbor and, Above All Else, Friend}

\begin{abstract}
In June 2021, Enrique Bustamante Ramírez, professor emeritus of Audiovisual Communication and Advertising at the Complutense University of Madrid, died at the age of seventytwo. Adelaida Bolea, honorary chair professor, takes us through some of the merits that marked his professional life. May this article from Área Abierta serve as a tribute to the memory of one of the journal's advisory board members.
\end{abstract}

Keywords: Enrique Bustamante; communication; cultural industries; education; university

Cómo citar: Bolea de Anta, A. (2022). Enrique Bustamante: colega, vecino y, sobre todo, amigo. Área Abierta. Revista de comunicación audiovisual y publicitaria 22 (1), 95-98, https://dx.doi.org/10.5209/arab.80085

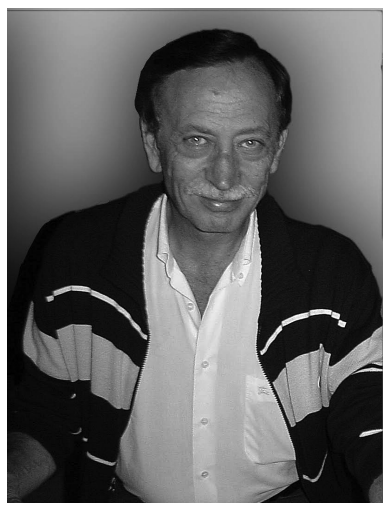

En octubre de 1986, la Universidad Complutense me contrataba para impartir la asignatura de Empresas de Radio y Televisión. Yo venía del ámbito de la empresa

1 Universidad Complutense de Madrid (España).

E-mail: adelaidabolea@ccinf.ucm.es

ORCID: https://orcid.org/0000-0002-5903-426X 
privada y no había oído hablar del profesor Enrique Bustamante, que en ese año había obtenido su plaza de profesor titular de universidad. Sin embargo, en aquellos días él ya era una celebridad en la facultad: un profesor admirado y temido a partes iguales por sus alumnos, a los que impartía la asignatura de Teoría de la Imagen. Una tarde de aquel año tuvimos un aviso de bomba, eran los años duros de ETA, la policía nos desalojó de la facultad y resultó ser un aviso falso; entonces alguien recordó que ese día había convocado un examen parcial del profesor Bustamante. ¿Casualidad?

Periodista, sociólogo y doctor en sociología, había sido redactor durante doce años en numerosos medios de comunicación, entre ellos cinco en la emblemática revista de oposición al franquismo Cuadernos para el Diálogo (1973-1978), en los que compartió redacción con periodistas de la talla de Joaquín Estefanía, Soledad Gallego, Vicente Verdú o José Antonio Gabriel y Galán.

Cuando llegué a la UCM trabajaba en un departamento distinto al de Enrique, pero las circunstancias del momento hicieron que un año después pidiera el cambio al Departamento de Comunicación Audiovisual y Publicidad 1 -CAP1-, con Antonio Lara como director. Ello supuso una declaración de guerra entre departamentos en los días en los que yo tenía que defender mi tesis doctoral; fue entonces cuando coincidí con el profesor Bustamante y me dijo: "No vamos a tolerar que esto afecte a tu carrera docente".

Un año después de mi paso al CAP1, Enrique fue elegido director del Departamento de Comunicación Audiovisual y Publicidad I de la Universidad Complutense (1989-1993). Fueron años duros: con más de once mil alumnos, cada grupo de comunicación y publicidad tenía unos quinientos alumnos matriculados. A Enrique aquello le parecía intolerable; la calidad de la enseñanza pública no podía llegar a ese grado de deterioro. Desde su posición como miembro de la Junta de Facultad, peleó en cada reunión de esta hasta conseguir el desdoblamiento de los grupos de comunicación y publicidad. Ahora había que reestructurar la docencia. Enrique consideró que, como director del departamento, debía dar ejemplo: dejó la asignatura de Teoría de la Imagen, que había impartido hasta entonces; fue ahí cuando comenzamos a compartir la asignatura de Empresas de Radio y Televisión y nuestras carreras universitarias se unieron.

A los pocos meses de acabar su etapa como director de departamento, fue nombrado secretario general y vicerrector de la Universidad Internacional Menéndez Pelayo (1993-1997) en el mandato del rector Ernest Lluch; el asesinato de Ernest a manos de la banda terrorista ETA le causó un profundo dolor y en el despacho que tenía en nuestra facultad siempre tuvo, desde entonces, un póster que le recordaba.

A finales de los años ochenta nos fuimos a vivir al mismo edificio y eso nos facilitó mucho las cosas: nos podíamos dejar documentos en el buzón de correos y después de poner notas en verano, en su casa o en la mía, sin prisas, como también hacíamos durante el curso en su despacho de la universidad, hablábamos de mil cosas, unas relacionadas directamente con la situación de la universidad en particular y de la sociedad en general, otras más personales. Nuestras madres eran muy mayores y vivían fuera de Madrid, la mía en Almería y la suya en Málaga; fueron muchos los momentos de confidencias por el sentimiento que creaba la distancia y, con la desaparición de las dos, muchos los recuerdos compartidos que nos consolaban de sus ausencias.

En 1990 fui invitada a presentar una ponencia en un congreso internacional de marketing y comunicación en el Tec de Monterrey (México). Cuando vas a una uni- 
versidad americana, en la que los profesores españoles somos queridos y respetados, solo piensas en volver. Desde ese momento, Enrique me ayudó a conseguir invitaciones para ir a universidades de Chile, Argentina, Uruguay y Guatemala. Sin duda, la experiencia más enriquecedora de mi carrera docente. Ayudar a profesores y alumnos en lo que fuera necesario es otra de las facetas humanas de Enrique que hay que destacar: muchos de mis actuales colegas de departamento le deben la consolidación de sus carreras docentes. Su permanente lucha por conseguir convocatorias de plazas para los profesores más jóvenes fue una constante durante su etapa de director del CAP1.

Dirigir un departamento tan grande y preparar una nueva asignatura no le apartaron de la investigación: fundó y dirigió o coordinó la revista Telos en las dos etapas de la revista y no perdía ocasión de animarnos a sus compañeros y alumnos de doctorado para que publicáramos en ella. Cuando en 1992 Enrique obtuvo la Cátedra de Comunicación Audiovisual y Publicidad en la Universidad Complutense de Madrid, los alumnos se sorprendieron: ellos pensaban que él ya era catedrático desde hacía tiempo. Además, fue el creador y coordinador del Programa de Doctorado y coordinador del Máster Universitario de Comunicación Audiovisual para la Era Digital.

La política y la investigación se cruzaron en su camino cuando, en el año 2004, el presidente del Gobierno, José Luis Rodríguez Zapatero, le designó como miembro y ponente del Consejo para la Reforma de los Medios de Comunicación de Titularidad del Estado; junto a él Emilio Lledó, Fernando Savater y Victoria Camps. Por su trabajo y aportaciones en esa comisión fue condecorado con la Gran Cruz de la Orden Civil de Alfonso X el Sabio (2005). Las universidades también reconocieron su valía como investigador: la Universidad Carlos III, la Universidad de Vigo y la Universidad de Extremadura, que le nombró doctor honoris causa en octubre de 2019, entre otras.

En paralelo a su labor universitaria e investigadora, mantenía su faceta de divulgador como profesor desde la Cátedra Unesco de Comunicación Internacional. También desde la presidencia y la vicepresidencia de CONFIBERCOM: una etapa fructífera en la que se puso en valor el papel de los investigadores en comunicación de Iberoamérica. Fue uno de los fundadores de la AEIC, de la que fue su vicepresidente entre 2008 y 2016, presidente electo en el Congreso de Madrid en Julio de 2016 y reelegido en el Congreso de Valencia en octubre de 2020.

Cuando nos dejó en 2021, la ANECA le había reconocido seis sexenios de investigación. Hacía dos años (2019) que había sido nombrado catedrático emérito de Comunicación de la UCM y los dos años anteriores (2017-2019) los había pasado, en comisión de servicios, en la universidad de su querida Málaga, en la que el Consejo de Gobierno lo había nombrado investigador distinguido. En ese tiempo, Enrique trabajó en la redacción de la Memoria del Instituto Andaluz de Investigación en Comunicación y Cultura (INACOM), un trabajo aprobado por los rectorados de las universidades de Málaga y Sevilla en 2019.

Varias semanas después de su marcha -aún me cuesta escribir sobre él en pasado-, me resulta difícil aceptar que tanto talento y tantos conocimientos puedan desaparecer para siempre. Pero nos queda su obra: tres centenares de artículos académicos y otras tantas monografías individuales o editadas, incluyendo capítulos de libros pero, sobre todo, nos queda el recuerdo de su calidad humana, su deseo de hacer grande la universidad pública y defenderla de los ataques espurios de quienes querrían que desapareciera en favor de la iniciativa privada; de su afán por investigar 
y aportar sus conocimientos a los alumnos en las clases de los centros en los que impartía docencia, en conferencias y seminarios; de su implicación personal para conseguir una sociedad más humana y más justa, en la que los intereses de unos pocos no primaran sobre las necesidades de muchos.

Los que tuvimos la suerte de estar cerca de él siempre recordaremos la ironía educada con la que atacaba a sus rivales -incontestable-, su gesto inmutable ante las críticas injustas de los que le envidiaban e incluso ante los miserables que le atacaban desde escritos anónimos y cobardes; siempre amable, siempre sonriente. En mi recuerdo permanece el cariño con el que siempre tenía una palabra amable cuando pasábamos por momentos difíciles.

Allá donde estés, te has ganado ser feliz. Adiós, amigo, hasta siempre. 